\title{
$\begin{array}{llll}K & R & \text { I }\end{array}$
}

Kriz Dergisi 11 (2) 19-27

\section{ÖFKE VE ÖFKE YÖNETIMi}

\author{
Çlŏdem Soykan*
}

\section{OZET}

Genel olarak ofke doyurulmamış ısteklere, Istenmeyen sonuçlara ve karşılanmayan beklentılere verılen duygusal tepkıđır Ofke dığer duygular gıbı son derece doğal, evrensel ve saglıklı olarak ı́ade edılı̆ğinde yapıcı ve kışıler arası l’etışımı duzeltıcı olabılen bır duygudur Ancak ofke kontrol edilemeyen ve yikıcı bir biçınde davranışlara yansıyarak saldırgan ve son derece tahrıp edıcı tepkılere donuşme potansıyelıne sahıptır Bu gun ıçın ev ıçı şıddet olgularında, çocuk tacız ve ıstısmarlarinda, teror olaylarında, sokak kavgalarında ve trafıkte sağłıklı olarak ıfade edılemeyen ofke duygularının etkısı gorulmektedir Genelde Insanlar ofke lle Ilgil olarak ne kadar sıkıntıları olsa da genellikle bu. nu kabul edıp konuyla Ilgılı yardım ıstemek yerıne ofke ve benzen duyguların daha çok bastırmaya, ınkar etmeye ve yok saymaya çalışırlar Bır çok çalışmada sağıkklı bıçımde ıfade edıle-

Dr Psk Psıkolojkk Mudahale Değerlendırme ve Eğıtım Merkezı Ankara

meyen ve bastırılmaya çalışılan ofkenın ıse kronık kalp damar hastailıklarına, baş ağrısına, yuksek tansıyona ve mıde hastalıklarına yol açarak kışının fızıksel sağlığı ıçın cıddı tehdıtter oluşturduğu tanımlanmaktadır Ofkenın ne bastırılması ne de Inkar edılmesı sağlıklt ve etkılı bır Ifade yolu olarak gorumemektedir Sonuçta her tur ofkenın kışıyı uyarıcı, koruyucu veya harekete geçırıcı bır ışlevı vardır Dolayısıyla ofke organızmayı bir problem olduğunda uyarır ve kendısıne zarar verıcı veya saldırgan davranma eğıımınden kış।yı haberdar etmede etkın bır rol oynar Ofkenın sağılıkı olarak yaşanıp ve yonetılebıımesı ıçın kabuıl edılmesı, nedenlerının ve bıçımının anlaşılması ve kesınlıkle saldırgan bıçımlerde ıfadesının kontrol edilmesı gereklıdir

Anahtar sozcukler: Ofke, saldırganlık, ofke ıle baş-etme

\section{Anger and Anger Management}

\section{ABSTRACT}

Anger is an expression of emotion in response to unsatısfied wishes, unwanted 
results and unfulfilled expectations Similar to all other emotional expressions, anger is a naturai and universal feeling that may improve communication if expressed appropriately on the other hand, uncontrolled and destructive anger may lead to aggressive and highly distruptive behaviour The impacts of uncontrolled anger can be seen domestic violence, child abuse, street and trafific fights Overall, people usually do not ask for help when they feel that they have problems with their anger, Instead, they prefer to suppress, deny or behave overtiy aggressively Unhealthy suppression of anger also causes many health problems including hypertention, headache and gastrointestinal symptoms Nelther suppression nor overexpression of aggression appears to be a healthy and efficious means of expressing anger Although anger is a signal for the organism that alerts itself for a danger or a problem, it may also alerts the person himself about the destructiveness evoked by anger In conclusion, anger should be expenenced appropriately, be understood and managed accordingly

Key words: Anger, Agression, Anger management

\section{GiRış}

Temel olarak ofke davranışı ı̧ın çozum arayan, kontrol edılmesı gerektığını duşunen ve bunun ıçın yardım arayan kişıler azınlıkta olmasına rağmen ofke, gunluk yaşantımızda sanıldığından daha fazla etkın olmaktadır Dunyanın bugun ıçınde bulunduğu zorłayıcı yaşam koşulları, guvenlığın ve sosyal guvencelerın yetersız oluşu, ekonomık koşulların atlelerı zorlaması ınsanları daha gergin, sıkıntılı, çaresız ve engel- lenmış hale getırmektedır Kışler bu engellenmelerm sonucunda krontk olarak uyarılmış ve gerılmış hale gelebılmektedıler Ancak, asıl sorun, gunluk yaşamda bır çok sorunla karşılaşmaktan çok, kışılerın kendilerınde hıssettıklerı ofkenın şiddetı ve bu tur duyguları uzerınde ne kadar kontrol sanıbı olduklarıdır Ofke başlıca uç objeye ılıskin ortaya çıkmaktadır, kışının kendısine, dığerlerıne ve başına gelenlere yanı yaşadiğı dunyaya karșı

Sonuçta ortaya çıkışı nastl olursa olsun, aslında ofke de dığer bı çok duygu gıbı anlaşılabilen, kabul edilebılen, kontrol edilebilen ve etkın bır bıçımde kullanıldığında ışe yarayabılen bır duygudur Bu yazıda gunumuz ortaminda ofkenin nasıl bir sorun olarak ortaya çıkabileceği uzerinde durularak, ofkenin belıttlen, ofkenin nasıl ve nıçin gelıştığı ve ofke lie başetme yolları tızerınde durulmuştur

\section{Ofkenın Tanımı, Nedenlerı, Anlaşı/ması}

Ofke, doyuruimamış ısteklere, Istenmeyen sonuçlara ve karşilanmayan beklențlere vertlen, son derece doğal, evrensel ve ınsan bır duygusal tepkıdır Ote yandan, belkı de en zarar verıcı olabılen duygusal yaşantı olarak da tanımlanabilır Kontrolsuz ofkentn hem birey hem de toplum uzerınde ınanılmaz bır etkısı vardır Ofke, genellıkle suça ve şıddete yonelık davranışlarla Ilgilı olarak eş ve çocuk tacızł orneklerınde, toplu şiddet olgularında kendın gostermektedır (Romas A ve Sharma M 2000) Bunun yanısıra ofke, kışlerarası sorunlu lışkılere, boşanmaya, çalişma yaşamında uretkenlığın ve ışlevsellı̆ı̆n bozulmasına, fizłksel ve ruhsal sağlıkta onemls sorunlara neden olabılmektedır (Martın $\mathrm{R}$ ve Watson D 1997) Gunluk yaşam ıçınde sıklıkla yaşanan bu duygu temelde en az ikı kışının mutsuzluğuna neden olmaktadır Ofke, hem yonel- 


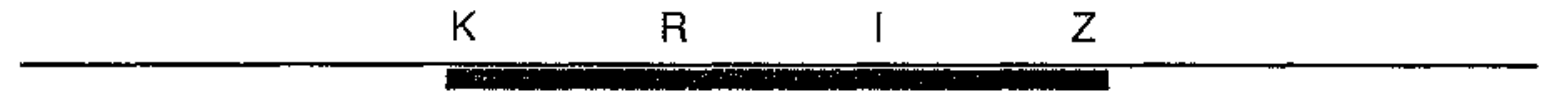

diğı hedefı hem de kaynağını olumsuz błr yaşantı ıçıne sokmaktadır Burada ofkeyı yaşayan ıçın, ofkenın kontrolı, ofkentn yoneldığı kışı ıçınse, gelen bu ofkeyle nası başedłleceğı onemlı bır sorundur Duygusal, fizyolojık ve btlşsel boyutiarda yaşanan ofkenın, yoğun ve istenmeyen etkılerı goz onune alındığında cıddı sorunlar ortaya çıkmaktadır

Dilımizde, tam bır benzerlik gostermeseler de kızgınlık ve ofke gıbı kelımeler bırbırlerının yerıne sıklıkla kullanılmaktadır (Bilge 1996) Bu tanımlamalara duşmanlık, hıddet ve şıddet gibı kavramlarda eklenebı!seler de aslında, saldırganlık olarak tanımlanabılecek şıddet durumları ofkenının davranışsal ve kontroisuz olarak ortaya çıkması ıçın kullanılırken, duşmanlık ıse ofkenın daha çok kronıkleşmış halıne ışaret etmektedir Literaturde Berkowitz (1993) duşmanca ve saldırgan davranışları benzer olarak değerlendırırken, Spielberger ve arkadaşları (1995) saldırganlığı ofkeden ve duşmancıl duygu ve tutumlardan ayrı olarak değerlendırmektedırler Spıelberger (1988) ofkenının orta şıddette bır rahatsızlık ve uyarılma halınden yoğun bı husumet ve saidırganlık durumuna kadar değıșen yoğunluklarda yaşanabıleceğını duşunmektedır Ofkenın en tehlıkelı sonucu olan şıddet ıçerıkı davranışların, ofkenın yoğunluğu tle yakindan ılgılı olduğu açıktır

Ote yandan, ofke, diğer duygularda olduğu gibı yargılanamaz Bıreyler, duygularina gore davranıp davranmayacaklarına kendılerı karar verırler Ofkenın tum olumsuz sonuçlarına karşın, aslında, kışıyı uyarıcı, koruyucu veya harekete geçırıcı olan ışlevlerı, bu duygusal yaşantıntn, yaşamın devamı ıçın ne kadar onemiı ofduğuna ışaret etmektedır Doğada bir çok cantının yaşamını surdurebılmesı ıçın, kendısı ıçın var olan tehdıllere karşı uyarılması ve kendısını korumak, yaşamda kalabılmek ve turunu surdurebıłmek ıçin saldırgan davranışlar gosterebılmesı gerekmektedir Dolayısıyla ofke bır taraftan organızmayı bır problem olduğu konusunda uyarırken, dığer taraftan da organızmanın kendısıne zarar verıcı veya saldırgan davranma eğılımının farkına varması konusunda etkın bır rol oynar (Smıth 1993) Ofkeyı ve guniuk yaşamımızdakı ışlevını daha ıyı anlamamızı sağlayabılecek bazı ozelıkler Tablo 1'de sunulmaktadır

Tablo 1. Otke nedır, ne işe yarar?
Ofke, son derece normal ve yaşamın surdurulmesı ıçın gereklı bır duygudur
Otke, duygusal bır tepkıdır
Ofke, uyarıcı bı ışarettır
Ofke, kışıyı tehdıtlere karşı uyarır ve kendısını korumasına olanak sağlar
Ofke, yen oğrenmeler ı̧̧ı bır molvasyon kaynağıdır
Ofke, sınırlandsrılabıldığı surece sağııkıdır ve ışe yarar
Ofke, kontrol edı̉medığınde kışının kendısı ve çevresı ıçın zarartı olabılır

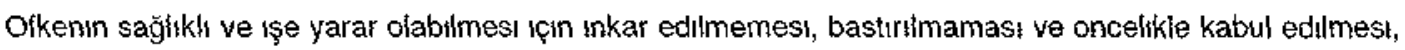 tanınması ve kontrołtu bır bıçımde Ifade edılebılmesı gerekır 
Kışı tarafından kabul edılen, anlaşılan, Ifade edılmeye çalışılan bır ofke duygusu etkın, ışe yarayan, uretken bır durumdur Oysa, kontrol edilemeyen, inkar ya da bastırma lle yok sayılan bu tur duygutar, kışının hem kendısı hem de çevresı ıçı zararit olma potansiyeli taşımaktadir Ote yaridan ofke, Tablo 2'de gorulen biçımde ışledığınde kışı ve çevresı ıçın zararı́ı sonuçlarla yaşanabıllecektir lhığı gıbı ruhsal bozuklukların yanısıra, ağrilı ve kronık seyırli bır fızıksel hastalığa sahıp oima da kışıde kronik ofke duygularına neden olmaktadir

Yoğun olarak yaşanan ofke duygulari, kışı ı̧̧ı saldırgan davranma eğılımını harekete geçırebilmektedir Saldırgan davranışlarda ise temel olarak başkalarına zarar verme nıyetı soz konusudur ve hem sozel hem de sozel olmayan bl-

Tablo 2. Ofke ne değildır?

\begin{tabular}{|ll|}
\hline & Ofke bır problem çozme aracı değıldır \\
$\cdot$ & Ofke bır oç alma veya ıntıkam yolu değıııır \\
$\cdot$ & Ofke başkalarını suçiama bıçımı değılııı \\
$\cdot$ & Ofke şłddet gostermeye veya suç ışlemek ıçın bır neden değıldır \\
$\cdot$ & Ofke başkalarını kontrol etme yolu değııdır \\
$\cdot$ & Ofke bır haklı olma yolu değıldır
\end{tabular}

\section{Ofke lle llgili Duygular}

B:ındłğı gıbı ofke ve dığer duygular arasında son derece karmaşık bır Iışki vardır Ofkenın anksiyete, suçluluk, depresyon, bağımilik ve cınsellıkle ılgısı gosterıłmektedır (Byrne\& Kelley 1981, Blaggio 1987, Riley ve ark 1989, Tangney 1996, Fava ve ark 1990) Asfinda kızgınlık, ofke gıbı duyguiarın daha çok ıkıncı duygutar olduğu, kırılma, ałınma, gucenme, anlaşılmama, reddedilme, engellenme, korku, kaygı, hayal kırıkığı, yalnızılık gıbı acı veren temel duygulara ıkıncıl olarak oluştuğunun birey tarafından anlaşılması onemlıdır (Gordon 1999) Ofke dıle getırımemış veya anlaşılmamış, kabul gormemış kızgınlıkların topluca yasanması ve ortaya dokulmesı olarak da ortaya çıkablıt

Bazı durumlarda ıse altta yatan depresyon, yas bıpolar bozukłuklar, madde ve alkol bağım- çımlerde ortaya çıkabılır (Spellberger ve ark 1995) Saldırgan davranıșlar soz konusu oidugunda ise artik brr kontrol kaybı soz konusudur Ofke ve kızgınlık asıında ıçsel bır duyguyken, saidırganlık gıbı yıkıcı davranışłar haiıne donuşebılmektedir Saldirganlık soz konusu oiduğunda ıse ortaya çıkan sonuçlar çok daha cıddı olmaktadır Bu nedenle, ofkenın belkı de en istenmeyen bıçımde ıfadesı olabilen saldırganlık dav ranışlarının, oncelıkle anlaşııması ve sonuçlarının kontrolu ıçın çalışılıması gereklıdır

Ofke ve duşmanca duygular ıle ılgilı olarak yapılan bazı yayınıarda, bu duyguların daha çok ofkenın kronık bır durumda yaşanmasına ışaret ettığı duşunuımekte ve hostılıte ıle saidırganlığın birbırlerine çok benzedıklerı ıfade edılmektedır (Berkowitz 1993) Hostıl ve ofkelı bireyler ciddı sağlık sorunlarına ve ozellikle kalp damar hasłalıkları, yuksek tansıyon, yorgunluk ve anksıye- 
tenın eşlik ettığı p stkosomatık bozukluklar, ulser ve baş ağrısı gıbı hastalıklara yatkın gozukmektedır (Frledman ve Rosenman 1974, Tavrs 1989, Ellot ve Bre o 1489 ) Fr erman (1991) kolej yıllarında hostli it a r izniarı yuksek olan bıreylerın, 20 yll sonrc, $\mathrm{rghellerne} \mathrm{gore} \mathrm{yuksek} \mathrm{ko-}$ lestrollu, aşır! kıloi!l i ho sk 'anciyonu dan, daha çok alkol ve $k a_{1}$... nui di a "slgara Içen ve genellikle daha çcr >ał’’k sorunu olan kışıler olduğunu gostermışı̆

\section{Ofke Sirasirida Ortaya Cikan ve Ofkeyı} Tanitan Belirti ve ışaretler

Ofke açıkca ve doğrudan gozlenebılen sozel ve davranışsi belruplar yoluyla gosterileblieceğ gıbı, yıne davranişsal ya da sozel ofarak, doğrudan olm?vis y oilarla da ifade edilebilir Tokat atma, fokmo fłma, vurma, yuksek sesle konuşma, kutur etme ya da tehdit etme, aşırı eleştırel olma, hata drama, tartışmacı ve saldırgan bır tavır ıçınde olma, ısım takma, sıçlama, alay etme, dedıodu yapma, şuphecilı, onyargiyla yaklaşma, orke nobetlen geçirme gibı açıkca, kışının başkal trinı ıncitmey! ya da çevre- ye zarar vermeyı ıstedığını gosteren sozel ve fizıksel tacızler genellıkle ofkenın doğrudan gorulebilen belıtı ve ışaretlerı olarak tanımlanabılmektedir (Madiow 1972)

Başkalarından uzak durma ve onlarla ışbırığını red etme, sessızlık, unutkantlik psıkosomattk hastalıklar, depresyon ve suçluluk duyguları, kazaya yatkınlık, ışbırlığıne karşı dırenç bağımılıı davranışları, aşırı alttan alıma, çekıngen davranma, ağlama, şıddete ve şuça yonelık fantazıler ıçınde buiunma, yoğun bır rahatsızık ve stress altında olma duygusu, mutsuzluk ve gerginlik, gucenıklik ve ruhsal acı çekme duygulasmın varlı̆ı głbı belıttler ıse ofkenun dolaylı olarak ıfadesın I ţeren belırtı ve ışaretlerdır (Madlow 1972, Hankıns 1993)

\section{Ofke Yonetim}

Ofke, ışlevsel olabılen bır duygu olmasına rağmen belırgın, gerı donulemez ve ceza gerektırır davranışların kokenınde yer alan bı duygu da olabılır Bu nedenle yıkıcl ofkentn kontrol edilmesı gereklidır Tablo 3'de ofke lie niçın başa çıkııması gerektığı anlatıımaktadır

\section{Tablo 3 Otke le nłçın başa çikmalıyız?}

\footnotetext{
- Ofke uygun bır bıç mde lfade edildıgınde son derece saglıkli bır duygudur Ancak tersı durumlarda ylkfcl etkılere yol açabilır

- Ofke çocuk istısmarı ev ıcı şıddet fizıksel ve sozel tacız gibł sorunlarda gorulebaleceğı gıbı bırçok sosyal ve kışısel problemın oraya çıkışında rol oynar

- Ofke kışler arası ılışkılerde problem yaşanan bırçok durumda onemı bı etkendır ve bıreylerin ış ve arle yaşantılanna ıışkın ckdd sorunların ortaya çikmasına neden olur

Ofke tle etkın bur bıçumde baş edememe ve kısıtlı problem çozme becetılerı nedentyle bırey sosyal ıışkılerden kaçını Ofke lle etkın bır bıcımde baş edememe sonucunda kışlerde sıgara kullanrna madde bagımlılıgı yeme bozuklukları depresyon gıbı sorun'ar açıga çıkabııır

Ofkeyı kontrol etme ıle ılgitı sorunları olan bıreyler sıklıkla dıger ctuyguların da uygun bır şekılde oftaya koyma guclugu cekerier ve bu kışılerde gerginlık stres gıbı ruh saglıgını tehtıd eden kronık problemter ortaya çıkablır

Uygun yollarla flade bulamayan ofke saldırganik ve duşmanlık duyguları kışlierde ciddı saglik problemlerı ortaya çıkarabulır Ozellikle ımmun sıstem kalp damar hastalıkları mıde bagırsak sıstem hastalıkları risklerl artar
} 
Ofkenın sağlıklı ve ışe yarar olabılmesı ıçın oncelıkle varlığının kabul edılmesı ve tanınması gerekır Ofkenın ı́adesı kışıden kışıye değışıklık gostermektedır Bazı kışıler bu tur duygularını sıklıkla bastırmayı, yok saymayı ya da ınkar etmeyı tercıh ederken, diğerlers ofkeyı bır sure bastırıp daha sonraları patlamalar şeklınde ifade eder Bır kısım bırey ıse ofke ıle davranmayı bır yaşam bıçım halıne getırmıştır Yukarıda sozu edılen davranışların varlığı genellıkle ofkeyle başetmede kullanılan çozumierin ışlevsel olmadığını gostermekte ve bu tur tepkıler çoğunlukla ofke ve kızgınlığın sağlıksız bıçımde Ifade edıdığıne ışaret etmektedır Bu bıçımlerde Ifade bulan ofkenın kışının yaşam kalıtesını onemlı olçude etkıledığı açıktır

Aslında ofkenın ifadesinde sadece ortaya koyma ya da bastırma tarzında ıkı seçenek yoktur, kışlerın kendı ofkelerını, kaynaklarını ve ofkeyı ortaya koyma bıçımınierını anlaması çok onemlıdır Ev odevlerı ve yaşantısal ornekler yoluyla bireylerın kend ofkelerin! tanıma ve anlama becerilerının gelıştırılmesıne çalışılır OfkeIt ve saldırgan davranışların bır problem çozme aracı, bır oç alma, ıntıkam yolu, başkalarını suçlama, şıddet gostermeye veya suç ışlemeye ozur, başkalarını kontrol etme yolu ve bır haklı olma yolu olmadığının anlaşıllmasına yonelık çaişmalar yaptilı Bu ozelikierın farkına varan brreyler ofkeyı ışlevsel olarak kullanabılmekte ve daha sağlıklı yollarla ıfade etmeyı becerebılmektedırler Genel olarak ofkenın uygun bır bıçımde ele alınabilınmesı konusunda yanı ofke yonetıminde kullanılan yontemler oldukça çeşıtıdır Burada onemlı olan kışının ıntıyaçlarının belırlenmesı ve bu intıyaçlar doğrıltusunda kuillanılabılecek uygun yaklaşımın bulunmasıdır Tablo 4'de daha çok ofke davranışın durdurmaya ve kontrol etmeye yonelik bazı onerıler sunulmuştur

Tablo 4. Ofkeyı denetlemeye yonelik genel onerter.

- Kendi ofkenızı tetıkleyen durumları ve ofkenızın bıçımını tanımlayın

- Kendı kendınızı sakınleştırmeye yonelık egzersızlerı duzenlı olarak yapın

- Derın nefes alın, nabız atışlarınızı ve nefesınızı kontrol aitına alın

- Kendınıze, sızı sakınleştırecek cumleler soyleyın

- Kendınızı, kontrol etrne konusunda kararlı olun Şıddete yonelik davranışları asla kabul edıllebılır çozumler olarak değertendirmeym

Ofke duygusuna evet ancak bu duyguyla davranmaya hayır, bağırmayın, vurmayın

Çevrenızdekılerı, ofkelendığınıze at bılgılendııın

Kendınıze zaman tanłyın Eğer mumkun ıse kendınızı ofkelı olduğunuz ortamdan hemen uzakiaştırın ve sotunla ancak kontrolunuzu yenıden kazandığınızda uğraşın

Problemı açıkıı̆ga kavuşturmaya çalışın ve çozumu aramaya odaklanın

Bol bol gułun ve espı yeteneğınızı kullanın olaya yenı bır bakış açısı ve yenı bır çerçeve kazandırın Kışısel saldırılara cevap vermeyın kışıselleştıłmekten kaçının 
Ofke davranışını kontrol etme yonundekı bır kısım çalışmalar basıt davranışlar ve duşunceler uzerinde durmaktadır (Lando ve Donnerstein 1978, Zullmann 1979, Moon ve Eisler 1983, Aranson 1984, Lewis ve Bucher 1992) Bu tur yontemlerde, kışının ofkelı ve saldırgan olabılen davranışiarını besleyen çevresel ozellıklerın değıştııımesı, daha uygun davranış* ların kazanılması, duşmanca ve suça yoneıık fantazilerın azaltılmasi ya da durdurulması, ofkenın kaynaklarının ve sonuçlarının kaydedımesı, saldırgan davranışların dıkkatın dağıtılması ya da esprı yoluyla azaitıması gıbı sonuçlar hedeflenmektedır Istenmedık bır şekılde ortaya çıkan ofke davranışında, engellenmenın ve stresle başetme becerılerındekı sınırlılığın yetersız olduğu durumlarda, stresle başetme, engellenmeye tahammulun artturıması ve gevşeme gıbı yontemier kullanılarak ofke davranışı kontrol edılmeye ve azaitı Imaya çalışılmaktadır (Novaco 1975, Leventha! 1984, Meichenbaum 1985, Suinn 1990)

Ofke davranışlarmın ortaya çıkışında, kışıleraras! ॥ışkıye ait bırçok sorunun ve yetersız problem çozme becerılerının etkılı olduğu bılınmektedır Bu durumda ofkeden korunmay ve azaltmayı hedefleyen bazı yaklaşımlarda etkılı ıletışım becerılerı, guvengen (atılgan) davranışların kazanılması, sosyal becerı eğıtımı, sosyal destekłerın kullanımı, problem ve çatışma çozumierı, empatık olma, çatışma çozumlerı ve duygusal kontrolun arttırılması gıbı kışılerarası \|ışkılerde etkın olmayı kolaylaştıran becerı eğıtımlerı onemsenmektedır (Lerner 1985, Greenberg 1992)

Ofkenın azaltılmasında kullanılan bır dığer tur yaklaşımda duşunce-duygu ve davranış uç- lusune mudahale eden, bilışsel yontem ve teknıklerdır Bu mudahalelerdekı temel amaç daha çok ofke davranışına ast gerçekçı ve fonksıyonel olmayan otomatık duşuncelerı belırleyerek, bunları gerçekçı ve fonksıyonel ołan alternatif duşuncelerle değıştırmeye ve denetlemeye yoneIIktır (Aronson 1984, Ellis ve Lange 1994, Ellis 1997)

Kışılerın kendı ofkelerını tanımalarının ve afttakı bır takım nedenlerı fark etmelerınınde ofke kontrolunde onemí olduğu duşunulmektedir (Tavrıs1989, Maslın 1994, Tedeschı ve Felson 1994) Bu tur yontemlerde, kışılertn bılınçaltı duygu ve ısteklerıne aıt ıçgoru kazanmaları, suçluluk, yetersızlık, değersızlık gıbı duygularını, onyargı gıbı tutum ve davranışlarını fark etmelerı ve değıştırmelerı ıçın çalışılır

\section{SONUÇ}

Ofke, sağlıklı olarak yaşandığında son derece Işlevsel olabtlen bur duyguyken, kontrol edılemedığınde hem kışı hem de çevresı ıçın oldukça zararlı olabılen bır duygudur Ote yandan ofke ve ofkenın ıfades: hakkındakı bilgllerımız çok sınırlıdır Bu yazıda ofkenın nedenler! ve ofke yonetımı anahatlartyla ele alınmış ve konunun onemıne dıkkat çekıımeye çalışılmıştır Konuyla ılgı!ı daha kapsamlı ve kullanılan yontemierın ışe yarar!ığını araştıran çalışmalara her zaman ıçın ıntıyaç olacağı açıktır 


\section{KAYNAKLAR}

Aronson $E$ (1984) The social animal $W H$ Freeman \& $\mathrm{Co}$, New York

Berkowitz L (1993) Aggression lis causes, consequences and control McGraw-Hill, New York

Blaggło MK (1987) Therapeutic management of anger Clinical Psychology Review, 7, 663-675

Bilge F (1996) Danışandan hiz alan ve bilışse!davranışcı yaklaşımlarla yapılan grupla psıkołojk danışmantn unıversıte oğrencllerının kızgınlık duzey* lerı uzerındekı etkilerı Yayınlanmamış doktora Tezı Hacettepe Universitesı-Sosyal Bilımer Enstitusu, Ankara

Byrne D ve Kelley K (1981) An introduction to personality (3rd ed) Prentice-Hall, Englewood Cliffs, NJ

Eliot RS ve Breo DL (1989) is it worth dying for?How to make stress work for you-nol against you Bantam, New York

Ellis A ve Lange A (1994) How to keep people from pushing your buttons Carol Press, Secaucus, NJ

Elis A (1997) How to control your anger before its controls you Carol Publishing Group, Secaucus $\mathrm{NJ}$

Fava M, Anderson K ve Rosenbaum J (1990) Anger attacks Possible variant of pantc and major depressive disorder American journal of Psychtatry. $\uparrow 47,867-870$

Friedman $M$ ve Rosenman RH (1974) Type A behavior and your heart Fawcett Crest, New york

Friedman HS (1991) Hostlity, coping, and health APA, Hyattsville, MD

Greenberg RP, Bornstein RF, Greenberg MD ve Fisher S (1992) A meta-analysis of antidepressant outcome under "blinder" conditions Journal of Counselıng and Clinical Psychology, 60, 664-669
Gordon T (1999) Etkııı anababa eğıtımı E Aksay ve $\mathrm{B}$ Ozkan (Çev) Ya-pa yayınları, Istanbul

Hankıns G (1993) Prescription for anger Warner Books, New York

Lando HA ve Donnerstein E (1978) The effects of a model's success or farlure on subsequent aggressive behavior Journal of Research in Personality, 12, 225-234

Lemer HG (1985) The dance of anger Harper \& Row, New York

Leventhal H (1984) A perceptual-motor theory of emotion In Berkowitz (Ed), Advances in experimental social psychology, Vol 13 (pp 117182) Academıc Press, New York

Lewis WA ve Bucher AM (1992) Anger, catharsis, the reformulated frustration-aggression hypothesis, and health consequences Psychotherapy, 29, 385-392

Madlow L (1972) Anger How to recognize and cope with it Schrioners, New York

Martın R ve Watson D (1997) Style of anger expression and its relation to dally experience Personality and Social Psychology Bulletin, 23 (3),284-294

Maslın B (1994) The angry marriage Overcoming the rage, reclatming the love Hypenon, New York

Mechenbaum D (1985) Stress inoculation traınıng Pergamon Press, New York

Moon JR \& Eisler RM (1983) Anger control an experimental comparson of three behavioral treatments Behavior Therapy, 14, 493-505

Navaco R (1975) Anger control The development and evaluation of an experımental treatment Lexington Books, Lexington Mass

Riley WT, Treber, FA ve Woods MG (1989) Anger and hostlity in depression Journal of Nervous and Mental Disease, 177(11), 668-674 
Romas A ve Sharma M (2000) Practical Stress Management Allyn\&Bacon, Massachusetts

Smith JC (1993) Creative stress management The 1-2-3 cope system Prentice-Hall, Englewood Clifts, NJ

Suinn RM (1990) Anxiety management training A behavior therapy Plenum Press, New York

Spletberger C (1988) State-tralt anger expression inventory Psychological Assessment Resources, Orlando, FL

Spellberg CD. Reheiser, EC ve Sydeman SJ (1995) Measurng the experience, depression, and control of anger ( $E d$ ) $H$ Kassinove, Anger
Disorders Defintion, Diagnosis and Treatment Tayior \& Francis

Tangney JP, Wagner P, Hill-Barlow D, Marschall DE ve Gramzow R (1996) Relation of shame and gult to constructive versus destructive responses to anger across the lifespan Journal of Personality and Socjal Psychology, 70(4),797-809

Tavris $C$ (1989) Anger The misunderstood emotion Simon \& Schuster, New York

Tedeschı JT ve Felson RB (1994) Violence, aggression, and coercive actions American Psychological Assoctation, Washington, DC

Zlimann D (1979) Hostilty and aggression Lawrence Eribaum Associates, Hillsdale, NJ

\section{Yazısma Adresi:}

Dr Çı̆dem SOYKAN

Psikolök Muduhale, Deḡerlendirme ve Eğtım Merkezi, Ankara

Uğur Mumcu Caddesı 13/1

Gazı Osman Paşa / ANKARA 